\title{
DOPING OF GaN BY ION IMPLANTATION: DOES IT WORK?
}

\section{A. SUVKHANOV *, J.HUNN **, W. WU ***, D. THOMSON ${ }^{* * *}$, K. PRICE* CONF- $980405--$ N. PARIKH", E. IRENE ${ }^{* * *}$, R.F. DAVIS ${ }^{* * *}$, L. KRASNOBAEV}

*Department of Physics \& Astronomy, University of North Carolina, Chapel Hill, NC 27599

"* Metals and Seramics Division, Oak Ridge National Laboratory, Oak Ridge, TN 37831-6376

*** Department of Chemistry, University of North Carolina, Chapel Hill, NC 27599

****** Department of Materials Science \& Engineering, NC State University, Raleigh ,

*****implant Center, San-Jose, CA 95131

Epitaxially grown $\mathrm{GaN}$ by metal organic chemical vapor deposition (MOCVD) on SiC were implanted with $100 \mathrm{keV} \mathrm{Si}^{+}$(for n-type) and $80 \mathrm{keV} \mathrm{Mg}^{+}$(for p-type) with various fluences from $1 \times 10^{12}$ to $7 \times 10^{15}$ ions $/ \mathrm{cm}^{2}$ at liquid nitrogen temperature (LT), room temperature (RT), and $700{ }^{\circ} \mathrm{C}(\mathrm{HT})$. High temperature $\left(1200{ }^{\circ} \mathrm{C}\right.$ and $\left.1500^{\circ} \mathrm{C}\right)$ annealing was carried out after capping the GaN with epitaxial AIN by MOCVD to study damage recovery. Samples were capped by a layer of AIN in order to protect the GaN surface during annealing. Effects of implant temperature, damage and dopant activation are critically studied to evaluate a role of ion implantation in doping of GaN. The damage was studied by Rutherford Backscattering/Channeling, spectroscopic ellipsometry and photoluminescence. Results show dependence of radiation damage level on temperature of the substrate during implantation: implantations at elevated temperatures up to $550^{\circ} \mathrm{C}$ decrease the lattice disorder; "hot implants" above $550^{\circ} \mathrm{C}$ can not be useful in doping of GaN due to nitrogen loss from the surface. SE measurements have indicated very high sensitivity to the implantation damage. PL measurements at LT of $80 \mathrm{keV} \mathrm{Mg}^{+}\left(5 \times 10^{14} \mathrm{~cm}^{-2}\right)$ implanted and annealed GaN showed two peaks : one $\sim 100$ $\mathrm{meV}$ and another $\sim 140 \mathrm{meV}$ away from the band edge.

\section{INTRODUCTION}

\section{DISTRIBUTION OF THIS DOCUMENT IS URLIMTTED}

In recent years attention to GaN related materials have risen because of potential and present applications, such as blue and ultraviolet light emitting diodes [1,2], blue lasers [3], UV detectors [4] and high-power and high-temperature FETs [5]. Regardless of the great success in the fabrication of optoelectronic and electronic devices, group III-nitrides suffer from difficulties in exhibiting the desired $\mathrm{n}$ - and p- type conduction [6-9]. Successful doping of $\mathrm{GaN}$ by ion implantation would be advantageous for device fabrication and therefore recovery of the implantation induced damage needs to be studied. So far there have been studies on ion damage generation and its partial recovery $[10,11]$. Additional studies are necessary to address the problem of effective doping of $\mathrm{GaN}$ by ion implantation. In this work we have performed implantations of $\mathrm{Si}^{+}$and $\mathrm{Mg}^{+}$in highly resistive epitaxially deposited GaN. Magnesium was chosen as the acceptor having low reported ionization energy, $-160 \mathrm{meV}$ [12]. Silicon was chosen as potential n- type dopant with reported ionization level $30-65 \mathrm{meV}[13,14]$. Implantations of silicon and magnesium were carried out at energies so that projected range of dopants would be $\sim 70 \mathrm{~nm}$ from the $\mathrm{GaN}$ surface. Implanted samples were capped by a layer of AIN grown epitaxially at $1000^{\circ} \mathrm{C}$ by MOCVD. Subsequently, samples were annealed at $1200{ }^{\circ} \mathrm{C}$ and $1500{ }^{\circ} \mathrm{C}$ in conventional furnace for 2 hours in the argon ambient. Activation of the implanted dopants after high temperature annealing was studied by Rutherford 


\section{DISCLAIMER}

This report was prepared as an account of work sponsored by an agency of the United States Government. Neither the United States Government nor any agency thereof, nor any of their employees, makes any warranty, express or implied, or assumes any legal liability or responsibility for the accuracy, completeness, or usefulness of any information, apparatus, product, or process disclosed, or represents that its use would not infringe privately owned rights. Reference herein to any specific commercial product, process, or service by trade name, trademark, manufacturer, or otherwise does not necessarily constitute or imply its endorsement, recommendation, or favoring by the United States Government or any agency thereof. The views and opinions of authors expressed herein do not necessarily state or reflect those of the United States Government or any agency thereof. 
Backscattering/Channeling (RBS/C), photoluminescence (PL), and spectroscopic ellipsometry (SE).

\section{EXPERIMENT}

Epitaxial GaN films grown on AlN buffer layers previously deposited on $6 \mathrm{H}-\mathrm{SiC}(0001)$ wafers and having dislocation densities on the order of $10^{7} \mathrm{~cm} / \mathrm{cm}^{3}$ beyond $0.5 \mu \mathrm{m}$ from the initial growth interface have been achieved via chemical vapor deposition (CVD). An absence of stacking faults and twinning in the implantation regions of the films make them the best materials available for the implantation doping study. Details of growth process and resulting films parameters are discussed elsewhere [15]. The deposited films were characterized by RBS/C with $1.6 \mathrm{MeV}$ and $2.0 \mathrm{MeV} \mathrm{He}{ }^{+}$with scattering angle $165^{\circ}$, and $\mathrm{PL}$ at low temperature $(77 \mathrm{~K})$ in vacuum and room temperature.

RBS/C measurements for the deposited $\mathrm{GaN}$ resulted in $\chi_{\min }$ less than $3 \%$ (ratio of aligned to random yield right after the surface peak) indicating excellent quality of MOCVD grown films. $\mathrm{Mg}^{+}$and $\mathrm{Si}^{+}$were implanted at liquid nitrogen (LT) and room temperatures (RT), and $700{ }^{\circ} \mathrm{C}(\mathrm{HT})$ to study the effect of implant temperature on the generation of disorder in the film. Implantation fluences were varied from $10^{12}$ to $7 \times 10^{15}$ ions $/ \mathrm{cm}^{2}$. The energies of dopants are calculated using TRIM code [16] to give an ion projected range of $\sim 70 \mathrm{~nm}$. As-implanted samples were analyzed with RBS/C, PL, and SE. Selected samples were capped with $\sim 30 \mathrm{~nm}$ AlN thereby preventing volatile component escape from the GaN. Capped samples were characterized with PL and SE. After this the capped samples were annealed at $1200{ }^{\circ} \mathrm{C}$ and 1500 ${ }^{0} \mathrm{C}$ in a conventional furnace in flowing Ar for 2 hours. Annealed samples were again characterized with PL and SE. He-Cd laser was used as the photoexcitation source $(325 \mathrm{~nm})$ for the PL experiment. The laser power was less than $100 \mathrm{~mW}$. The spectrometer was a $0.85 \mathrm{~m}$ double-grating instrument with a GaAs PMT. The slits were 500 microns. The LT measurements were performed using a Joule-Thompson refrigirator.

\section{RESULTS}

RBS/C study of as-deposited samples of GaN showed very good channeling along the $\mathrm{C}$ axis. The RBS/C data demonstrated that even at the highest fluence $7 \times 10^{15}$ ions $/ \mathrm{cm}^{2}$, a comparatively high dose, the implantation damage did not reach the random level. $\mathrm{The}^{\mathrm{Mg}}{ }^{+}$ implants showed a lower damage level compared to $\mathrm{Si}^{+}$implants, however the lowest dose of $\mathrm{Mg}^{+}$was enough to generate enough lattice damage to suppress the PL signal.

Fig. 1 (a). and Fig. 1 (b). demonstrate dependence of the level of disorder $\chi$ on the implant temperature. In the case of LT implants the induced damage level is higher than that at RT suggesting that RT implantation undergoes partial annealing. From the measured $\chi$ the HT implants reveal different processes for the generation of disorder in film with the production of a higher density of defects on the surface. This can be explained by considering a gradual degradation of the GaN surface layer with the loss of nitrogen. Thus, "hot implants" at temperatures higher than $550^{\circ} \mathrm{C}$ can not be utilized to dope $\mathrm{GaN}$. 

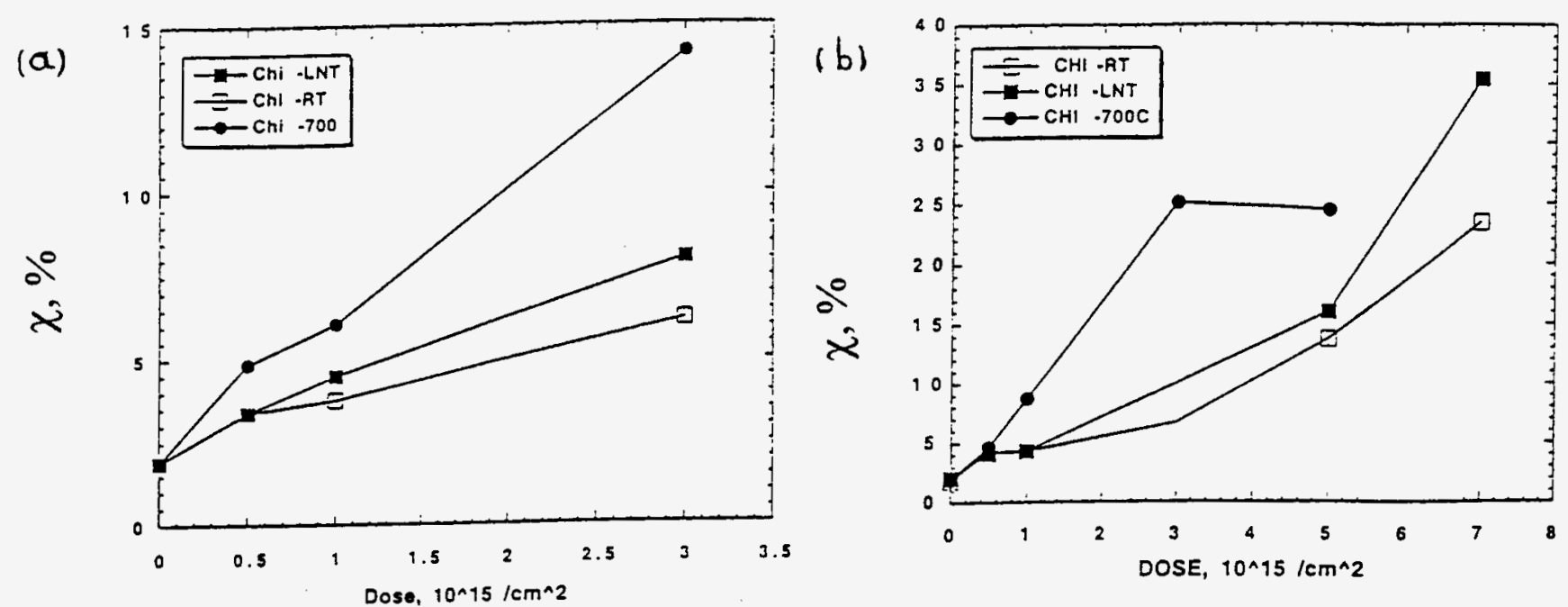

Fig. 1. Disorder $(\chi)$ from channeling for LNT, RT and $700{ }^{\circ} \mathrm{C} 80 \mathrm{keV}$ (a) $\mathrm{Mg}^{+}$and (b) $\mathrm{Si}^{+}$implantations respectively as a function of fluence.

The RT photoluminescense of unimplanted GaN is shown in Fig. 2 (a).
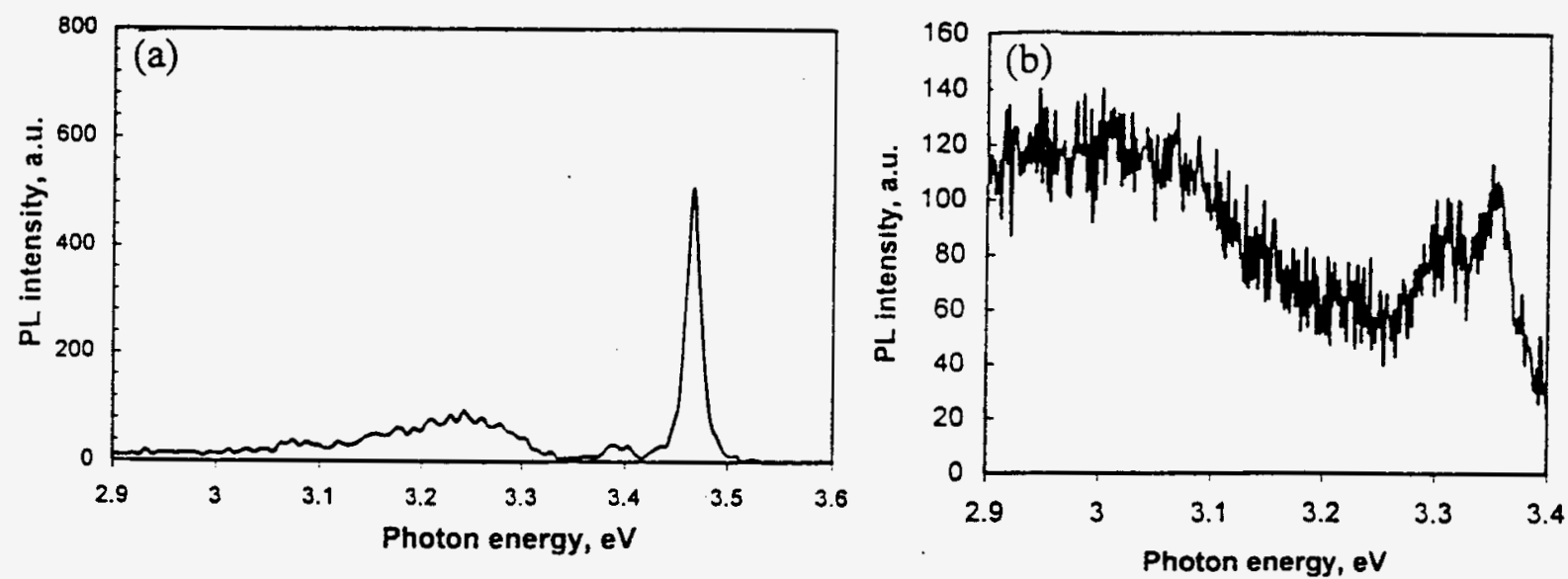

Fig. 2. PL spectra taken (a) at room temperature for as-deposited 2.3 micron thick $\mathrm{GaN}$ and (b) at LT for $80 \mathrm{keV} \mathrm{Mg}$ implanted, dose $5 \times 10^{14} \mathrm{~cm}^{-2}$. The sample was capped by $\sim 30 \mathrm{~nm}$ epitaxial AIN prior to annealing $\left(1200^{\circ} \mathrm{C}, 30 \mathrm{~min}\right.$ in $\left.\mathrm{Ar}\right)$.

As-implanted GaN sample did not give any PL signal. The peak at $3.465 \mathrm{eV}$ is attributed to the recombination of excitons at neutral donors. The FWHM of the peak was $186 \mathrm{meV}$.

Mg-implanted and annealed GaN (Fig. 2 (b)) resulted in two peaks near the band edge. First peak is located $\sim 100 \mathrm{meV}(3.348 \mathrm{eV})$ from band edge, the second is $\sim 140 \mathrm{meV}$ ( $3.31 \mathrm{meV})$ away from band edge. The first peak can be related to a $\mathrm{Mg}$ acceptor-bound exciton. The nature of the second peak needs to be investigated. Low intensity can be justified by partial recovery of 
lattice damage. According to the spectra the ionization level is less than previously reported 160 $200 \mathrm{meV}$ [12]. We think that the the broad peak at $\sim 3 \mathrm{eV}$ is due to defect luminescence in the substrate.

Spectroscopic ellipsometry (SE) was used to measure $\mathrm{n}$ (refractive index) and $\mathrm{k}$ (damping coefficient) for virgin, as-implanted and annealed samples. The sensitivity of SE to the implantation induced damage level can be observed in Fig. 3 (a) $\left(100 \mathrm{keV} \mathrm{Si}^{+}\right.$implantation at LT) and Fig. 3 (b) (80 $\mathrm{keV} \mathrm{Mg}^{+}$implantation at LT).
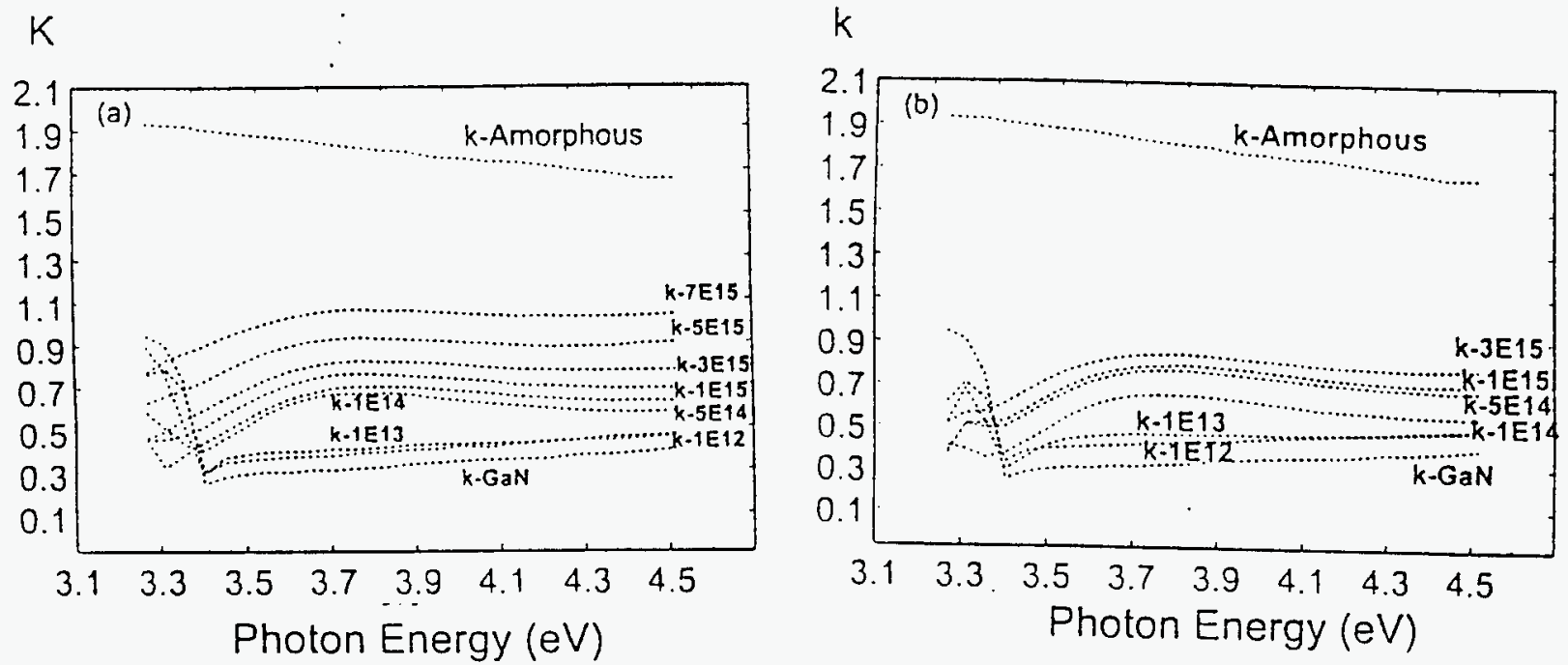

Fig. 3. Spectroscopic ellipsometry data for $\mathrm{k}$ for LT (a) $100 \mathrm{keV} \mathrm{Si}^{+}$and (b) $80 \mathrm{keV}$ $\mathrm{Mg}^{+}$implanted $\mathrm{GaN}$ as a function of dose.

Both figures show the absorption (or damping) coefficient plotted as a function of photon energy. $\mathrm{k}$ increases with the implantation fluence as is expected since damage creates more photon absorbing sites. In ongoing experiments we have reduced the ion energies [17] thus making the implant shallower in order to get the SE response near vicinity $(\sim 40 \mathrm{~nm})$ the implant distribution peak, so that it would give better correlation with RBS/C results. Selected implanted samples were annealed at $1200^{\circ} \mathrm{C}$ and $1500^{\circ} \mathrm{C}$ after capping with AIN. Our past annealing up to $1100^{\circ} \mathrm{C}$ did not restore the PL signal. However, RBS/C results showed significant annealing at $1100^{\circ} \mathrm{C}$. As the temperature of the sample was increased during implantation, the damage level was reduced [17] as is shown in Fig. 4. This is expected since at high temperature one expects dynamic annealing during implantation. It presents dose dependence of $\mathrm{k}$ as a function of photon energy. The coefficient $k$ can be related to damping level of the material, level of implant induced disorder. SE measurements are sensitive enough to distinguish difference in defect density created by implant fluence of $1 \times 10^{12} \mathrm{~cm}^{-2}$ from the virgin measurements.

Fig. 4 presents the absorption coefficient $\mathrm{k}$ (taken at $3.7 \mathrm{eV}$ ) vs. implant dose for various implantation temperatures. For higher fluences dependence on implantation temperature is pronounced. The values of $\mathrm{k}$ presented in Figures 3- 5 were collected at the photon energies higher than $\mathrm{E}_{\mathrm{g}}$ : $\mathrm{GaN}$ is almost transparent for photon energies below $\mathrm{E}_{\mathrm{g}}$; at energies higher than $E_{g}$ the film becomes opaque, and absorption spectra for the material show features. Fig. 5. shows the influence of capping on the improvement of $\mathrm{k}$ values for $\mathrm{Si}$ and $\mathrm{Mg}$ implanted samples. 


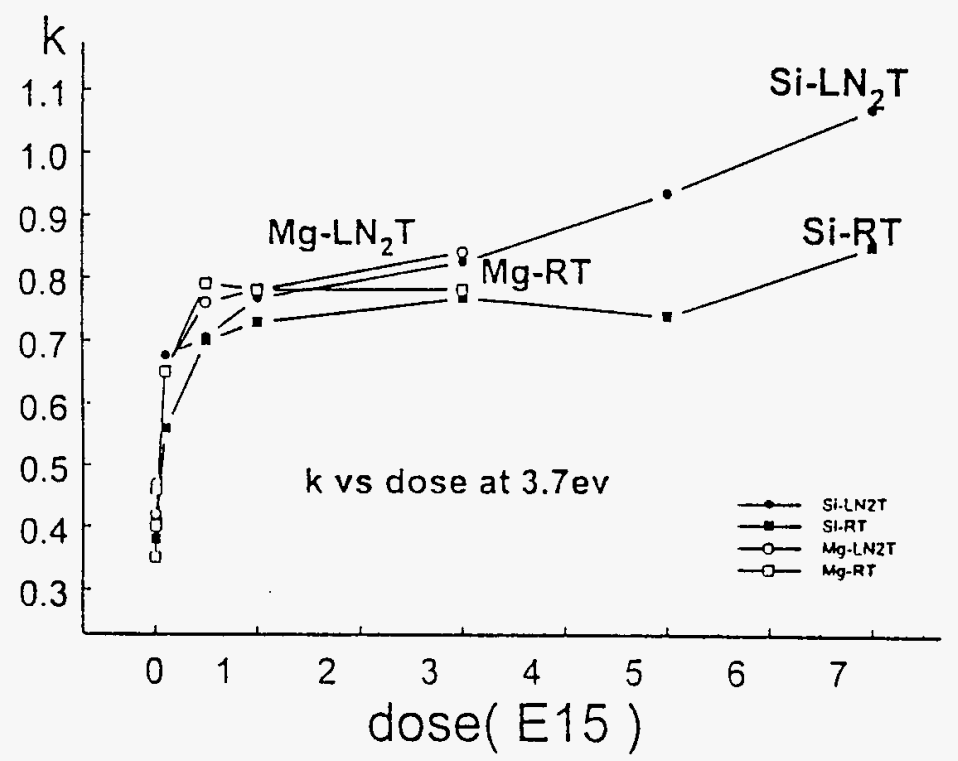

Fig. 4. Spectroscopic ellipsometry data for $\mathrm{k}$ for $100 \mathrm{keV} \mathrm{Si}{ }^{+} \mathrm{LT}$ and $\mathrm{RT}$ implants and $80 \mathrm{keV} \mathrm{Mg}{ }^{+} \mathrm{LT}$ and $\mathrm{RT}$ implants as a function of dose.

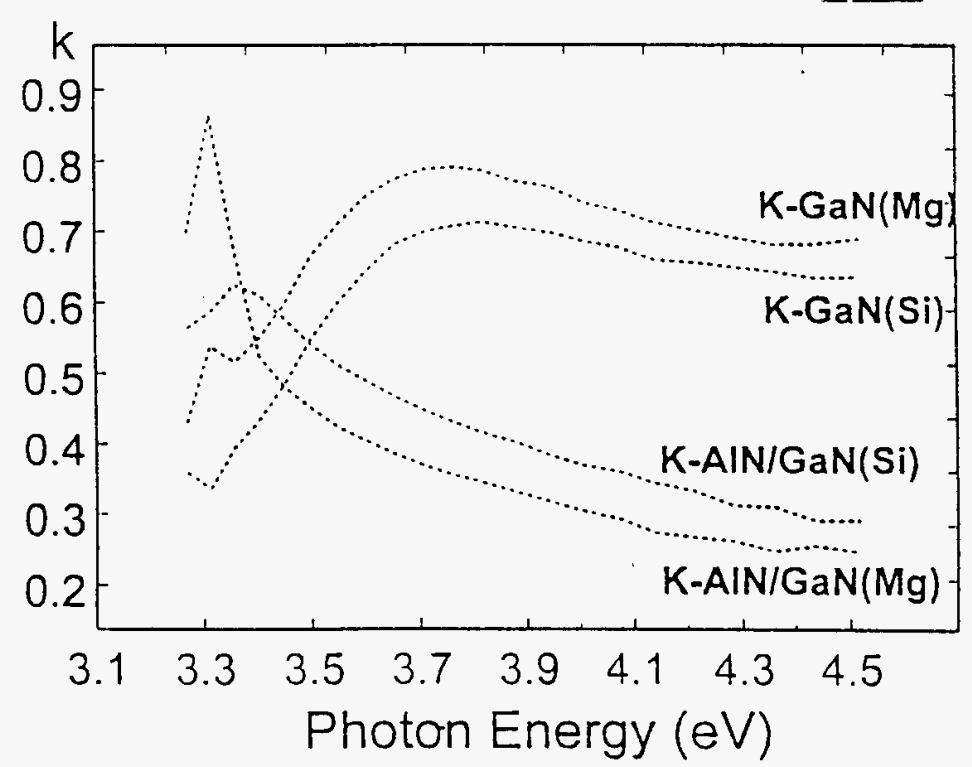

Fig. 5. Spectroscopic ellipsometry data for $k$ for capped and uncapped $\mathrm{GaN}$ as a function of photon energy.

\section{CONCLUSIONS}

$100 \mathrm{keV} \mathrm{Si}^{+}$and $80 \mathrm{keV} \mathrm{Mg}{ }^{+}$with various fluences from $1 \times 10^{12}$ to $7 \times 10^{15}$ ions $/ \mathrm{cm}^{2}$ were implanted at liquid nitrogen temperature, room temperature, and $700{ }^{\circ} \mathrm{C}$. RBS/C measurements showed high resistance of $\mathrm{GaN}$ to radiation damage. Recovery of implantation damage for high fluences are very difficult, hence to get high activation efficiency one needs to implant small fluences and anneal in between to recover the damage. Also, to optimize the damage recovery we are exploring recoil implantation concept through AlN capped layer. The HT implants, according to the measured $\chi_{\min }$, reveal different processes in the generation of disorder in the film, the production of higher density of defects on the surface due to gradual degradation of the GaN surface layer, and loss of nitrogen. Thus, "hot implants" at temperatures 
higher than $550^{\circ} \mathrm{C}$ can not be utilized to dope GaN. PL data for annealed capped $\mathrm{Mg}$-implanted GaN resulted in two peaks near the band edge: $100 \mathrm{meV}$ and $140 \mathrm{meV}$. The first peak can be related to $\mathrm{Mg}$ acceptor-bound exciton. The nature of the second peak needs to be investigated. This level of ionization is less than previously reported (160-200 meV). SE measurements are sensitive enough to distinguish difference in defect density for even very low $\left(1 \times 10^{12} \mathrm{~cm}^{-2}\right)$ implant doses.

\section{ACKNOWLEDGMENTS}

The authors are grateful to Holger Knauss, Chris Bower and Sean Rubio for their help with high temperature annealing. Special thanks to Dr. Steve Withrow (ORNL) for assistance and valuable discussions. The authors would also like to acknowledge partial support of SURA. ORAU/ORNL 1997 Summer Cooperative Research Program. Research is sponsored in part by the division of Materials Science , U.S. Department of Energy, under contract no.

DE-AC05-960R22464 with Liockheed Martin Energy Research Corporation.

\section{References}

1. H. Sakai, T. Koide, H. Suzuki, M. Yamaguchi, S. Yamasaki, M. Koike, H. Amano and I. Akasaki, Jpn. J. Appl.., 34, L1429 (1995).

2. S. Nakamura, M. Senoh, N. Iwasa and S. Nagahama, 1995 Appl. Phys. Lett., 67, 1868 (1995).

3. S. Nakamura, M. Senoh, S. Nagahama, N. Iwasa, T. Yamada, T. Matsushita, H. Kiyoku and Y. Sugimoto, Jpn. J. Appl. Phys., 35, L74 (1996).

4. M. Razeghi and A. Rogalski, J. Appl. Phys., 79, 7433 (1996).

5. M. A. Khan. M. S. Shur, J. N. Kuznia, Q. Chen, . J. Burm and W. Schaff, Appl. Phys. Lett., 66, 1083 (1995).

6. B. Goldenberg, J. D. Zook and R. J. Ulmer, Appl. Phys. Lett., 62, 381 (1993).

7. C. R. Abernathy, J. D. Mackenzie, S.J. Pearton and W. S. Hobson, Appl. Phys. Lett., 66, 1969 (1995).

8. R. Kaplan, S. M. Prokes, S. C. Binari and G. Kelner, Appl. Phys. Lett., 68, 3248 (1996).

9. K. Wongchotigul, N. Chen, D. P. Zhang, X. Tang and M. G. Spencer, Mater. Letter, 26, 223 (1996).

10. H. H. Tan, J. S. Willians, C. Yuan and S. J. Pearton, MRS Symp. Proc. Vol. 395, 807 (1996).

11. J. C. Zolper, J. Of Crystal Growth, 178, 157 (1997).

12. I. Akasaki, H. Amano, M. Kito and K. Hiromatsu, J. Lumin., 48/49, 666 (1991).

13. W. Gotz, N. M. Johnson, C. Chen, H. Liu, C. Kuo and W. Imler, Appl. Phys. Lett., 68, 22 (1996).

14. J. C. Kim, A. C. Frenkel, H. Liu and R. M. Park, Appl. Phys. Lett., 65, 91 (1994).

15. T.W. Weeks, Jr., M.D. Bremser, K.S. Alley, E. Carlson, W.G. Perry and R.F. Davis, Appl. Phys. Lett. 67 (1995) 401.

16. J.F. Zeigler, J.P. Biersak and U. Lirmark, in :The Stopping and Range of lons in Matter, Vol. 1 (Pergamon, New York, 1985).

17. N. Parikh, A. Suvkhanov, M. Lioubtchenko, E. Carlson, M. Bremser, D. Bray, R. Davis and J. Hunn, Nucl. Instr. and Meth. in Phys. Res. B 127/128 (1997) 463 


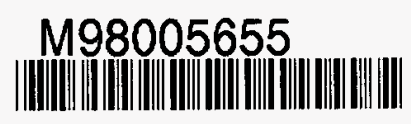

Report Number (14) ORNL/CP--98016
CONF-980405--

Publ. Date (11) $\frac{199804}{D O E / E R, X F}$
Sponsor Code (18)
UC Category (19) UC-400, DOE/ER

19980702045 DITC QUAJTY IVPPECTED 1 